\title{
Research on the Present Situation and Countermeasures of Mathematics Teaching in Higher Vocational Colleges in Sichuan Province
}

\author{
Lei Jiang \\ Chengdu Textile College \\ Chengdu, China 611731
}

\begin{abstract}
Through investigating and visiting the mathematics teaching and development in many higher vocational colleges in Sichuan province, this paper analyzes and studies the present situation and existing problems of mathematics teaching in higher vocational colleges in Sichuan province, and puts forward a series of suggestions, such as providing a platform for mathematics teaching in higher vocational colleges in the whole province, steadily advancing stratified teaching according to the school situation, combining with the characteristics of higher vocational colleges, strengthening the curriculum construction of mathematics experiment, promoting the cooperation of colleges and improving the construction of teaching staff and so on.
\end{abstract}

Keywords-Sichuan; higher vocational colleges; mathematics teaching; present situation; countermeasures

\section{INTRODUTION}

Mathematics teaching in higher vocational colleges has always been a problem that needs to be solved for a long time ${ }^{[1][2]}$. Because of the poor students' base, how to make students better learn mathematics, to serve the profession, and to improve the quality of talent training, we have to think from the curriculum construction of the school, the teachers, the students and so on [3], [4].

\section{PResent Situation OF Mathematics Teaching IN Higher Vocational Colleges in Sichuan PROVINCE}

The author randomly selects 21 higher vocational colleges in Sichuan, including 4 state-level demonstration colleges. Comprehensive and detailed investigations have been conducted in form of visits, questionnaires, exchange meetings, and listening to reports for the teaching of mathematics in these colleges. The specific statistics are as follows:

\section{A. The Basic Situation of Offering College Mathematics Courses}

Of all the schools studied, every school offers the teaching of university mathematics, including higher mathematics, economics mathematics, engineering mathematics, linear algebra, probability theory, quantity statistics and super sketchpad, which have a common feature: the courses of higher mathematics, engineering mathematics and linear algebra are mainly offered for the majors of science and engineering, while the courses of economics mathematics, probability theory and quantity statistics are mainly offered for the majors of cultural management and agriculture and medicine. There are 18 schools offering higher mathematics courses, accounting for $85.7 \%$ of the schools surveyed. Fifteen colleges and universities offer courses of economic mathematics, accounting for 71.4 percent. There are 6 schools offering courses of engineering mathematics, accounting for 28.6\%; in addition, 6 other schools offer mathematics courses such as linear algebra, probability theory and mathematical statistics separately, accounting for $28.6 \%$. One university also offers super sketchpad mathematics course, which accounts for 4.8 per cent. Among them, 20 schools took higher mathematics and economic mathematics as public basic courses, accounting for 95.2 percent; one school takes these two courses as professional basic course, accounting for 4.8 percent.

Of the institutions surveyed, four take the course of Higher Mathematics or Economic Mathematics as a mandatory course in one academic year, accounting for only $19.1 \%$, while the remaining 17 either open only one semester, or only make it a mandatory course in the first semester of the freshman year. In the second semester, it is made an elective course for students to choose, accounting for $80.9 \%$ of the school surveyed. In terms of the number of hours offered in the courses of Higher Mathematics and Economic Mathematics, the total teaching hours are mainly between 45 , $60,80,90,120$ and 150 hours. In the first semester of the freshmen year, eight schools offer 90 hours, accounting for $38.1 \%$; Eleven institutions offer 60 hours, accounting for 52.3 percent, and one institution offers 45 hours, accounting for 4.8 percent; One institution offers 80 hours, accounting for 4.8 per cent; By the second semester of the freshman year, 10 schools offer 30 hours, accounting for 47.6 percent; another 8 schools offer 60 hours, accounting for 38.1 percent and three institutions no longer offer, accounting for 14.2 percent. Among the schools that offer engineering mathematics courses, one offers 90 hours, three offer 60 hours and one offers 45 hours. In addition, there are three schools that offer 60-hour courses in linear algebra and probability and quantitative statistics, and one offering 40 hour super sketchpad courses specifically for art students. 
From the perspective of the curriculum assessment, all the colleges and universities adopt the two assessment programs of examination and inspection, and mainly use the usual performance final examination results as the final results of the students, but a very few schools also refer to the results of the students' mathematical experiments.

From the perspective of the textbooks used in the research schools, a very prominent feature is reflected: textbooks used by each school are basically different, so it is difficult to find a unified textbook. In the 21 colleges the authors investigate, 16 different textbooks are used in the course of higher mathematics alone. The teaching content also reflects a common point: no matter what kind of teaching materials is used, the teaching content is basically the same. For example, the teaching contents of higher mathematics mainly include monadic calculus, multivariate calculus, ordinary differential equation, and series and so on. There are also 5 schools that have joined the teaching contents of mathematics experiment, occupying only $23.8 \%$ of the research schools.

\section{B. Feedback on College Mathematics Courses}

Of the 21 colleges and universities surveyed, 17 consider the university mathematics curriculum is very important and necessary to offer, which is accepted by most of the students, accounting for $80.9 \%$ of the survey schools. There are also four colleges and universities thinks the learning is more difficult because of the poor foundation of students, and it can't reflect the immediate effect in life, so students have little interest in it, and their enthusiasm is not high. Such schools account for $19.1 \%$. The author divides the need for mathematics of students' professional knowledge into three levels: strong, average and weak. Among them, 13 institutions think it is strong, accounting for $61.9 \%$, six institutions think it is general, accounting for $28.6 \%$, and two institutions think it is weak, accounting for $9.5 \%$. From the students participating in the math modeling competition in recent years, students from 11 colleges and universities participated in team, accounting for $52.3 \%$, and students in 9 colleges and universities have won national and provincial awards, accounting for $42.6 \%$.

\section{Situation of School Faculty}

In all the colleges and universities we investigated, the proportion of teachers with higher professional titles is relatively small, and the proportion of teachers with higher academic qualifications and higher academic degrees is not prominent. The number of schools with the proportion of professors and associate professors over $50 \%$ is only three, only accounting for $14.3 \%$, and the number of schools with the proportion of postgraduate and higher education over $50 \%$ is only eight, accounting for $38.1 \%$.

\section{Schools' Attention to College Mathematics Curriculum}

The authors divide the degree of emphasis of college on university math curriculum into four levels: very high, high, average and low. Eight of the schools choose higher, accounting for 38.1 percent, while the remaining 13 choose average, accounting for 61.9 percent.

\section{Difficulties AND PROBlems IN COLLEGE MATHEMATICS TEACHING IN HighER VOCATIONAL SCHOOLS IN SICHUAN PROVINCE}

Through the investigation and analysis of the present situation of mathematics teaching in the above colleges and universities, it is believed that there are the following difficulties and problems:

\section{A. There Are Many Kinds of Textbooks and It Is Difficult to Unify Them}

There are a lot of textbooks about college mathematics in the society nowadays. Although the new textbooks are novel, the language is very concise; the content arrangement is also in line with the modern age, and the choice of exercises is closer to reality, some textbooks are compiled hastily because of time, some contents and exercises are not arranged properly, and most textbooks focus on theory, lacking more practical cases and applications related to the profession. Therefore, blind use of various textbooks may bring many problems. For example, the calculus part in some textbooks is too superficial, and the basic training is far from enough, which affects the understanding of calculus thought and the practicability as a mathematical tool. Most of the textbooks do not aim at the actual situation of the students, and do not combine the special requirements of the relevant majors for mathematics, making the students feel that there is no relationship between mathematics and the majors, which leads to the situation that they are tired of learning, do not learn and even hate mathematics ${ }^{[5]}$.

\section{B. Various Contradictions Are Outstanding}

1) The contradiction between quality education and vocational education: In most of the schools investigated, the characteristics of vocational education are mainly reflected, but as the teaching of university mathematics in higher vocational colleges, in addition to serving their own major, there is an important role of cultivating students' mathematical quality. We found that mathematics teaching in most of the school highlights one problem: students are only required to be able to calculate, solve problem and simply apply, but it is far from enough for the cultivation of students' creative application ability, which simply cannot embody the characteristics of quality education.

2) The contradiction between the high starting point of mathematical knowledge and the low overall quality of students: Due to the continuous expansion of college enrollment, the number of students has increased sharply in recent years, which also brings about prominent problems. Essentially, the university mathematics curriculum is relatively difficult with higher starting point, so if the student's foundation of mathematics in the middle school period is not firm, the university mathematics will add more difficulties for them after entering the university. The investigation finds that, in the colleges investigated, only in 6 national demonstrative higher vocational colleges and 2 higher vocational colleges, the proportion of students who 
passed mathematics in college entrance examination is more than $60 \%$ while the proportion in other higher vocational colleges is only more than $40 \%$, or even less than $20 \%$. The students' overall math quality is relatively low, which makes it difficult to learn math well.

3) The contradiction between teaching quality and teaching environment, teaching methods and teaching methods: How to guarantee teaching quality is the ultimate goal of teaching reform and teaching research. The survey finds that some schools, because of the large number of students and the relative lack of teachers, adopt the form of large-class teaching in the organization of teaching. Because of the large number of students, the management has brought great inconvenience to teachers, which leads to serious phenomena such as absenteeism for no reason, coming late and leaving early, attending lessons less carefully, and copying homework and so on, and the quality of teaching is seriously declining. In terms of teaching methods and means, all the schools mainly adopt the traditional teaching mode of blackboard writing in class. Some schools add multimedia such as slide, projection, and video recording and so on, although these ways can also integrate the picture and text, but interaction between teachers and students is still lacking, and students can not actively participate in the classroom teaching, which makes it difficult to inspire students to study independently and cultivate their interest in learning, leading that teaching quality cannot be guaranteed.

\section{The Reform of Mathematics Teaching in Colleges and Universities Varies Greatly}

Different colleges and universities have different hardware facilities and different students' qualities, including teaching environment and faculty, which lead to the inconsistency of mathematics teaching reform. For example, the mathematics experiment teaching has not been involved in many schools. As a very important national math competition project: mathematical modeling has not been carried out in many higher vocational colleges. These aspects show the disadvantage of uneven development.

\section{There Are Some Deviations in the Guidance of School Policy}

About $70 \%$ of the teachers in the colleges visited and surveyed complain that university mathematics course is paid little attention in their schools.

It is a dispensable curriculum, the number of classes is entirely determined by the professional leaders, and the interests of mathematics teachers cannot be protected. The math teachers in some colleges and universities even have no class to teach, so they either are engaged in administrative work, or switch to teaching other courses; some policies in colleges and universities also result in teachers attaching importance to scientific research and ignoring teaching. Teaching is only a soft index in the assessment of professional titles and all kinds of evaluation of teachers.
These policies have severely affected teachers' teaching enthusiasm and enthusiasm for work.

\section{THE COUNTERMEASURES AND SUGGESTIONS OF College MatheMATICS TEACHING IN SICHUAN HigheR VOCATIONAL AND TECHNICAL SCHOOLS}

\section{A. To Provide the Teaching Platform of Higher Mathematics in Higher Vocational Colleges}

Advanced Mathematics Courses are offered in almost every school, but for reasons of geographical location, school situation, and teaching environment, the higher mathematics in various institutions is different from each other in terms of teaching hours, teaching contents, teaching requirements and teaching materials. In order to strengthen the standard and quality control of higher vocational mathematics teaching in Sichuan Province, and to carry out teaching research, it is possible to try to provide teaching platform for higher vocational mathematics teaching in the whole province according to different majors and categories, and to promote classification teaching in an all-round way. Specific measures can be taken as follows:

We can divide higher mathematics into four categories according to the subject, organize well-known experts, professors and teachers in the province, and compile a set of high-quality textbooks for higher vocational colleges in the province to refer. The contents can be referred as follows:

- Advanced Mathematics (1) (science and engineering): 150 hours. The category that has a higher requirement for mathematics in science and engineering. Suitable majors: electromechanical, communication, computer science and technology, automation, and civil engineering and other specialties. Specific contents include: monadic calculus, ordinary differential equation, vector algebra and space geometry, multivariate calculus, linear algebra and probability preliminary, series, Laplacian transformation and mathematical experiments.

- Advanced Mathematics (2) (economics and management): 120 hours. The category that has general requirements for mathematical in economics and management. Suitable majors: Engineering Management, Information, Business Administration, International Trade, Accounting, and Chemistry, etc. Specific contents include: monadic calculus, ordinary differential equation, linear algebra preliminary, probability theory and mathematical statistics preliminary and mathematical experiments.

- Advanced Mathematics (3) (agricultural medicine, cooking): 120 hours. Medicine, agriculture and other majors that have basic requirements of mathematics. Suitable major: agronomy, nursing, medicine, and cooking and other related majors. Specific contents include: monadic calculus, ordinary differential equation, linear algebra preliminary, probability 
preliminary, statistical preliminary and mathematical experiments.

- Advanced Mathematics (4) (humanities): 90 hours. Arts and humanity that have general requirement for mathematics. Suitable major: art, design, secretarial, and foreign language and so on. Specific contents include: monadic calculus, logic, linear algebra preliminary, probability preliminary, statistical preliminary and mathematical experiments.

\section{B. Different Colleges and Universities Steadily Promote Stratified Teaching According to the Situation}

If the classification teaching is implemented, the main problems that may exist in the teaching are: similar students have large differences in the ability to learn mathematics; students have great differences in the interest in mathematics and the basis, and coexistence of liberal arts students and science students. In view of these possible problems, we can try to further implement the thought and practice of teaching at different levels on the basis of classification teaching in university mathematics. The general guiding ideology is: in the same class of college mathematics teaching, the students are divided into three levels: higher requirements, high requirements and basic requirements based on the principle of students' willingness. For the students who have the ability to learn and have a higher demand on mathematics, they can receive systematic and deeper mathematics teaching in the school. For students with poor learning ability and basic requirements for math, schools will set the basic requirements for college math for these students.

To implement these guidelines, the following diverse and flexible approaches can be adopted:

- To prepare a unified syllabus and test syllabus for each course organization; compile teaching proposal for the main teaching material according to the outline of the exam, set the basic requirements in the teaching proposal, and put forward the essential skills.

- For those students who have outstanding learning ability and are keen on mathematics knowledge, we actively provide learning opportunities and conditions and learning environment, such as advanced class in the form of public elective classes, or even tutorial classes for graduate school exam and so on.

- To carry on the research of the reform of the hierarchical mathematics teaching actively, and make further promotion through observation, summary, and absorbing many years' teaching experience.

\section{Strengthen the Curriculum Construction of Mathematics Experiment Course Combining with the Features of "Application-oriented" in Higher Vocational Education}

Mathematics experiments course is a kind of teaching activities with strong practical significance where under the guidance of teachers, students use the knowledge of mathematics theory and computer science and technology to strengthen mathematics theory and mathematical thinking and improve the analysis and solution of practical problems. The offer of mathematics experiment courses not only cultivates students' innovative consciousness, but also strengthens students' ability to think independently and make full use of mathematical knowledge to solve practical problems, and greatly enhances students' interest in mathematics learning. Through interviews and research, it is found that in the colleges that offer or add mathematics experiments, the feedback information is positive, and teachers and students are very happy to add this part of the teaching content. This could be done as follows:

- One or more mathematics laboratories should be set up in each university, which can be used specifically for the teaching of mathematics experiment courses, so as to lay a solid foundation for the smooth development of mathematics experiment courses.

- The theory is set up with the experiment, and the progress is consistent After theory teaching, adding the content of mathematics experiment can not only deepen students' understanding of the theory they have learned, but also help them apply the theory to practical problems vividly and intuitively, which will greatly promote students' grasp and understanding of knowledge.

- Aiming at different mathematics courses, different mathematics application software is used. For example, for higher mathematics, economic mathematics, and linear algebra and so on, maple and matlab software can be used while for probability and statistics related courses, spss software can be combined with. For the mathematical problems involving planning and operation, lindo and lingo software can be chosen to use.

- They can attempt to set up mathematics experiment courses related to students' majors in some majors with poor math foundation. For example, one of the schools we investigated specifically offers a super sketchpad math course for architectural art students. Although it belongs to the category of mathematics, it is combined more with computer, and introduces some geometrical knowledge to students through the software, which can be organically combined with the major of students, fully mobilizing students' learning enthusiasm and receiving a good effect.

\section{To Strengthen the Communication and Cooperation among Colleges and Universities and Further Strengthen the Construction of Teaching Staff}

Although there are many higher vocational colleges in Sichuan province, the distribution is relatively wide, and the exchange between teachers is very little, which makes it difficult to achieve resource sharing, hindering the common development of university mathematics teaching in higher 
vocational colleges in Sichuan province. We suggest that we can improve this situation through the following work.

- We can establish the Guiding Committee of Mathematics Teaching in Higher Vocational and Technical Colleges by selecting famous professors, experts and teachers from all vocational colleges as members of the steering committee to strengthen the guidance of mathematics teaching and carry out the regular and non-periodic reform and exchange work in mathematics teaching in the province, so as to promote the further development of mathematics teaching in higher vocational colleges in the whole province.

- The leading schools and teachers can be organized to compile textbooks reflecting the latest teaching achievements to recommend to other schools for study and reference. They should give full play to the leading and radiating role of state-level demonstrative higher vocational colleges and help other colleges to develop together.

- We should cultivate backbone teachers and subject leaders, and build a group of high-level teaching teams and innovative teams. We can try to set up the University Mathematics Teaching Achievement Award in the whole province to encourage the teachers of various vocational colleges to carry out teaching research and reform. At the same time, it is necessary to strengthen exchanges and cooperation among colleges and universities, send a group of middle-aged and young backbone teachers to wellknown universities inside or outside the province each year for study and restudy, improve the system for further training of mathematics teachers throughout the province, and vigorously strengthen the training of young teachers.

\section{CONCLUSION}

Through the investigation of the mathematics teaching and development of Higher Vocational Colleges in Sichuan Province, we have analyzed and studied the present situation and existing problems in mathematics teaching. We suggest that the school situation promote the stratified teaching steadily, combine the characteristics of higher vocational education, strengthen the construction of the curriculum of mathematics experiment, promote the cooperation of colleges and universities, and improve the construction of the teachers' team. A series of improvement measures are given.

\section{REFERENCES}

[1] Liu Xiaomin. Research on the Present Situation, Problems and Countermeasures of Teaching Evaluation of Higher Vocational Education [J] Chinese Vocational and Technical Education, 2005 (11).

[2] Wang Hongqi, Yu Jun, Qi Wenzhong. On the Significance of Constructing the Standard System of Vocational Skills Training [J] Education and Vocation, 2005 (36).

[3] Xu Diyu, Xia Peng. A Preliminary Study on the Integration of Science Education and Humanities Education in Higher Vocational
Colleges [J] Journal of Sichuan Vocational and Technical College, 2007 (03).

[4] Li Fang. Research on Implementing Developmental Teacher Evaluation in Mathematics Classroom Teaching of Health Vocational School [J] Journal of Shandong Normal University, 2006 (04).

[5] Huang Qinan. Zou Huichao. Humanistic Spirit of Mathematics and Its Value in Mathematics Education [J] Journal of Mathematics Education, 2006 (04). 